Journal of Applied Pharmaceutical Science Vol. 6 (03), pp. 159-171, March, 2016

Available online at http://www.japsonline.com

DOI: $10.7324 /$ JAPS.2016.60330

ISSN 2231-3354 (cc) BY-NC-SA

\title{
Recent Advances and Future Prospects of Phthalimide Derivatives
}

\author{
Neelottama Kushwaha ${ }^{\mathrm{a} *}$, Darpan Kaushik ${ }^{\mathrm{b}}$ \\ ${ }^{a}$ Pranveer Singh Institute of Technology, Kanpur, India. \\ ${ }^{\mathrm{b}}$ Prasad Institute of Technology, Jaunpur, India.
}

\section{ARTICLE INFO \\ Article history: \\ Received on: 21/05/2015 \\ Revised on: 13/09/2015 \\ Accepted on: 02/11/2015 \\ Available online: 10/03/2016}

Key words:

Phthalimide derivatives,

imide, biological activity.

\begin{abstract}
Among bicyclic non-aromatic nitrogen heterocycles, phthalimides are an interesting class of compounds with a large range of applications. Phthalimide contains an imide functional group and may be considered as nitrogen analogues of anhydrides or as diacyl derivatives of ammonia. They are lipophilic and neutral compounds and can therefore easily cross biological membranes in vivo and showing different pharmacological activities. In the present work compounds containing phthalimide subunit have been described as a scaffold to design new prototypes drug candidates with different biological activities and are used in different diseases as, for example AIDS, tumor, diabetes, multiple myeloma, convulsion, inflammation, pain, bacterial infection among others.
\end{abstract}

\section{INTRODUCTION}

Phthalimides possess a structural feature $-\mathrm{CO}-\mathrm{N}(\mathrm{R})$ $\mathrm{CO}$ - and an imide ring which help them to be biologically active and pharmaceutically useful. Phthalimides have received attention due to their androgen receptor antagonists (Sharma et al., 2012), anticonvulsant (Kathuria and Pathak, 2012), antimicrobial (Khidre et al., 2011), hypoglycaemic (Mbarki and Elhallaoui, 2012), anti-inflammatory (Lima et al., 2002), antitumour (Noguchi et al., 2005), anxiolytic (Yosuva and Sabastiyan, 2012) and anti HIV-1 activities (Sharma et al., 2010).

Several reports demonstrated the antimicrobial potential of phthalimide derivatives (Santos et al., 2009). Phthalimide derivatives of amino acid analogues possess anthelmintic activity (Srinivasan et al., 2010). There is a growing interest in the usefulness of phthalimides and its derivatives. They have found relevance as inhibitors of tumor necrosis factor production (Okunrobo et al., 2006). Phthalimides

\footnotetext{
* Corresponding Author

Neelottama Kushwaha, Assistant Professor, Department of Pharmacy,

Pranveer Singh Institute of Technology, Kanpur, India.

Tel: +91, 9452166918; E-mail: neelottama@gmail.com
}

have served as starting materials and intermediates for the synthesis of many types of alkaloids and pharmacophores.

\section{Structure of Phthalimide}

Phthalimide is an imido derivative of phthalic acid. In organic chemistry, imide is a functional group consisting of two carbonyl groups bound to nitrogen. They are hydrophobic and neutral, and can therefore cross biological membranes in vivo. These compounds are structurally related to acid anhydrides (Azzawi and Razzak, 2011).

In N-Benzyl phthalimide the benzene and imide groups are planar and make a dihedral angle of $74.2(1)^{\circ}$ with one another. There are three weak $\mathrm{C}-\mathrm{H}_{n}, \mathrm{O}$ hydrogen bonds, forming a twodimensional network structure. Most of the imides are cyclic compounds derived from dicarboxylic acids and their names reflect the parent acid.

Examples are succinimide derived from succinic acid and phthalimide derived from phthalic acid. As imide has the formula $\mathrm{NH}$, being highly polar, imides exhibit good solubility in polar media. The $\mathrm{N}-\mathrm{H}$ centre for imides derived from ammonia is acidic and can participate in hydrogen bonding. 


\section{Effect of neighboring carbonyl groups on acidity of N-Bond}

Imides such as phthalimide readily dissolve in aqueous

$\mathrm{NaOH}$ as water-soluble salts. Imides are more acidic than amides. The order of acidity $\mathrm{N}$ - bond given in figure 1:

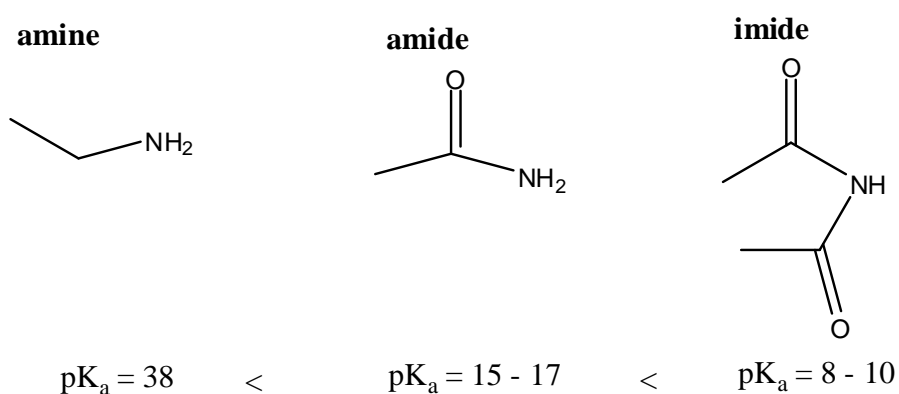

Fig. 1: increasing order of N-H acidity.

Phthalimide is highly acidic in nature due to it easily donate the proton and form water soluble salts with stronger bases. Reaction for salt formation is given in figure 2 :

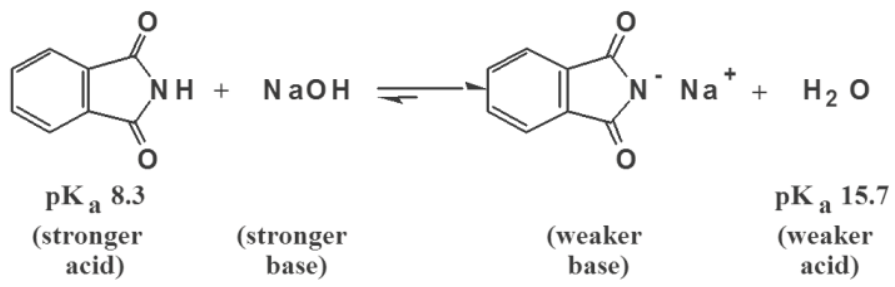

Fig. 2: Phthalimide salt formation with strong base.

Imides are more acidic than amides because:

1. The electron-withdrawing inductive of the two adjacent $\mathrm{C}=\mathrm{O}$ groups weakens the $\mathrm{N}-\mathrm{H}$ bond

2. More resonance delocalization of the negative charge.

Phthalimide have resonance stabilized structures which are shown in figure 3:

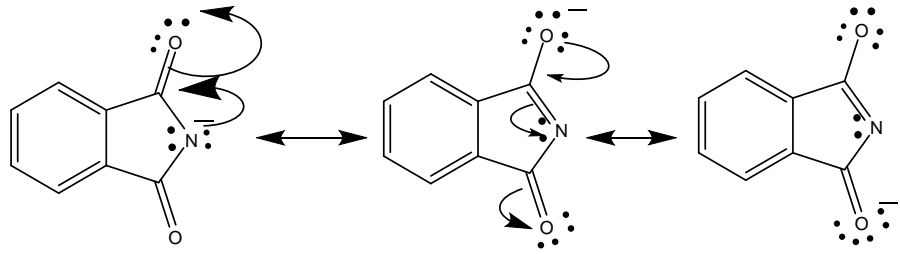

Fig. 3: A Resonance-stabilized anion.

Often, Phthalimides are oxidative stable, heat retardant, solvent resistant, and have superior mechanical properties. The specific reactivity of imides is a result of the relative acidity of the $\mathrm{NH}$ group, a direct consequence of the presence of the two carbonyl groups.

It is also observed that the metal complexes are more active than the free organic ligand. Chelation reduces the polarity of the metal ion and enhances the lipophilicity or hydrophobicity of metal chelate which favours its permeation through microbial cell wall. The metal chelates may also disturb the respiration process of the microbial cells and thus protein synthesis and further growth of the microorganism is hindered. Though the co- ordination of aliphatic tertiary amino nitrogen is not sterically favored, the high electron density available on the tertiary amino nitrogen favors its coordination to a metal ion where there is a possibility for chelation (Ramesh and Sabastiyan, 2012).

The phthalimide moiety serves as a 'protected' form of ammonia. The phthalimide carbonyls increase the acidity of the nitrogen (thus allowing formation of its conjugate base). Most importantly, the phthalimide carbonyls protect the nitrogen from 'over alkylation' thus preventing the formation of quaternary ammonium salts. N-benzoyl phthalimide resembles both classical benzodiazepines and barbituric acid structure. It consists of tricyclic hydrophobic structure comparable to that of benzodiazepines and possesses a conjugated ureid functional group as can be found in barbiturates. Size and tridimentional structure of benzodiazepines and phthalimide backbones are similar (Hassanzadeh et al., 2011).

Phthalimide and N-substituted phthalimides are an important class of compounds because they possess important biological activities the identifiable structural features for their activity are as: hydrophobic aryl ring, a hydrogen bonding domain, an electron-donor group, another distal hydrophobic site Bhat and Al-Omar (2011). 4-(phthalimide)-substituted phenoxy propanolamines also possessed cardioselective $\beta$-adrenergic receptor binding affinity (Jindal et al., 2005). Some marketed pharmaceutical products of phthalimide derivatives are reported in table 1 .

Table 1: List for biological active some reported phthalimide derivatives.

Use
Fangicide




\section{Preparation of phthalimide moiety}

Some synthetic reactions for preparation of phthalimide moity summarized in scheme 1 :

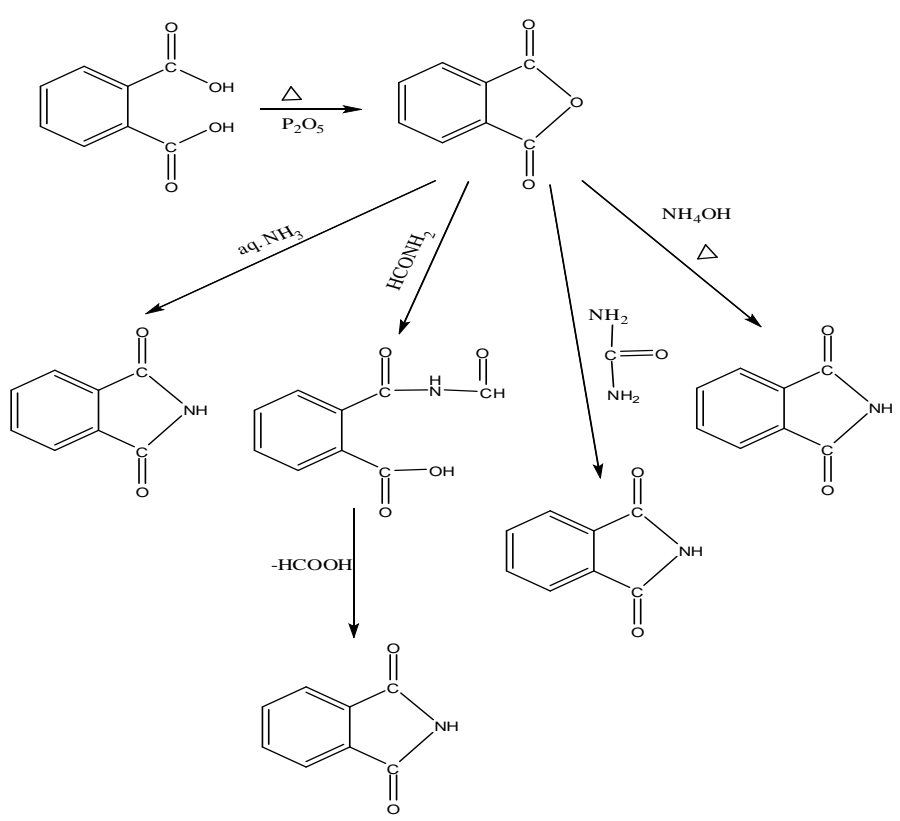

Scheme. 1: Reactions for preparation of phthalimide moity.

\section{Mathews Reaction}

The Mathews' reaction, a 'dry' hydrolysis procedure of nitriles by phthalic acid or amides by phthalic anhydride to give the corresponding carboxylic acid and phthalimide. Mathews' reaction is given in scheme 2 :<smiles>[2H]C#N</smiles>

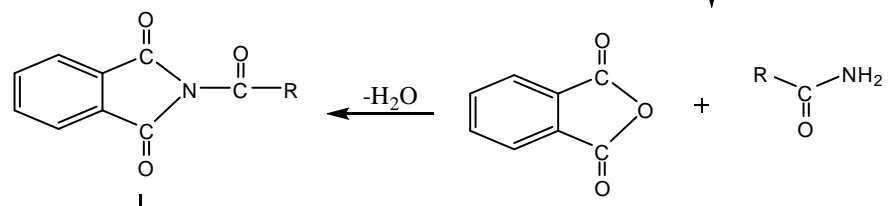<smiles>O=C(O)COC1NC(=O)c2ccccc21</smiles>

Scheme. 2: Synthesis of phthalimide by Mathews' reaction.

Chiriac et al., (2007) reported that aromatic or aliphatic cyclic imides and their derivatives are obtained by the reaction of dicarboxylic acids or their corresponding anhydrides with reagents bearing a reactive amino $\left(-\mathrm{NH}_{2}\right)$ functional group, through a nucleophilic attack of amino group to a anhydride moiety, by mechanism presented in figure 4 :
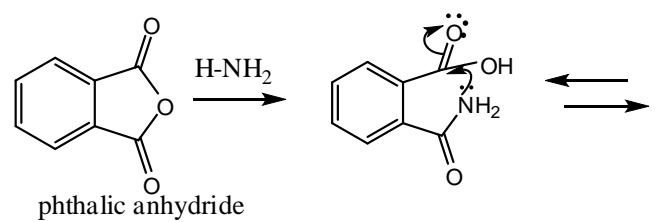<smiles>O=C1N[C@@]([O-])(O)c2ccccc21</smiles><smiles>O=C1NC(=O)c2ccccc21</smiles><smiles>CC1(O)NC(=O)c2ccccc21</smiles>

Fig. 4: Mechanism of imide formation by direct condensation.

A general and interesting synthetic pathway for the synthesis of imides by direct condensation using cyclic anhydrides or their corresponding dicarboxylic acids and form amide which is a simple affordable reagent. This approach has the advantage that this specific reagent can also serve as solvent, especially for aliphatic imides. For aromatic cyclic imides with lower solubility in formamide, another appropriate solvent can be supplementary used in order to maintain a homogeneous reaction medium and to allow the main product to be obtained in high yields. Synthesis of phthalimide in presence of formamide reagent given in scheme 3 :

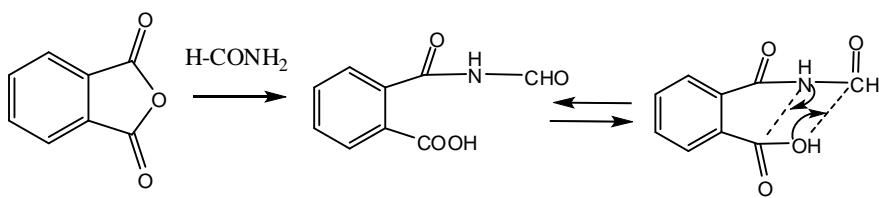

phthalic anhydride

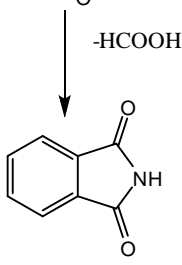

phthalimide

Schem. 3: Synthesis of imides in the presence of formamide as reagent

\section{BIOLOGICAL ACTIVITY OF PTHALIMIDE DERIVATIVES ALONG WITH SAR STUDY}

\section{Cytotoxic Activity}

Stanton et al., (2008) demonstrated that presence of benzothiazole unit attached to nitrogen of phthalimide, exhibits cytotoxic activity (compound $\mathbf{1}$ ) carried out 'one pot' condensation reaction for the synthesis of phthalic imide derivative (benzothiazole containing phthalimide), exhibiting in vitro cytotoxic potential on human cancer cell lines. They further reported that both caspase dependent and independent pathways were involved in the induction of apoptosis in cancer cells. Khokra et al., (2011) synthesized some benzothiazole containing 
phthalimide derivatives were found to exhibit in-vitro cytotoxic potential on human cancer cell lines.

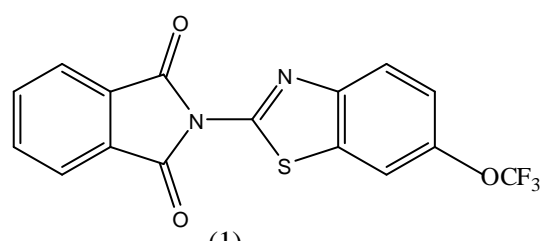

(1)

Singh et al., (2011) designed and evaluated anticancer activity of some novel isoindoline-1, 3-dione derivatives. It may act due to multiple events or apoptosis inducer. The compounds 2 and $\mathbf{3}$ showed significant anticancer activity. It may be due to chloro-phenyl ring attached to the isoindoline-1, 3-dione with ethyl groups respectively or the compound 2 at 2, 4 positions $d i$ chloro-substitution and in compound $\mathbf{3}$ chloro-substitution at 4 positions of phenyl ring. From the structural point of view, the chloro group which has the electron withdrawing property may be the crucial for tumor weight inhibition and tumor cell inhibition.

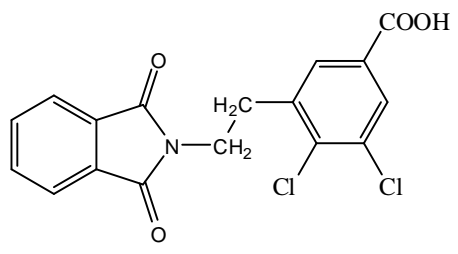

(2)

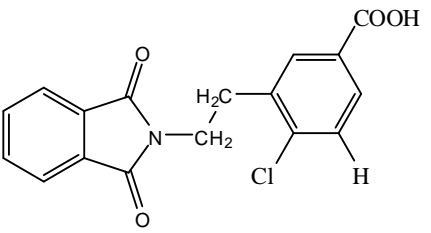

(3)
The isoindoline-1, 3-dione derivatives were evaluated for in vivo anticancer activity against the Ehrlich Ascites Carcinoma bearing mice model. Male Swiss albino mice were used as test animals. The synthesized compounds were administered intraperitoneally at a dose of $20-25 \mathrm{mg} / \mathrm{kg}$ body wt. per day for seven days after $24 \mathrm{hrs}$ of tumor inoculation in mice.

The standard drug used was 5-Fluorouracil $(20 \mathrm{mg} / \mathrm{kg}$, b. wt.). Compounds treated (III-VII) groups were found to reduce the body weight, tumor volume, packed cell volume, viable cell count and increase the tumor weight (\%) inhibition, ascites cells (\%) inhibition and non-viable cell count and Increase in life span $(\%$ ILS). Compound 2 showed the highest inhibition of cancerous cell growth compared to compound 3. From the present study, it can be concluded that isoindoline-1, 3-dione derivatives might have potent anti-proliferative activity.

Yang et al., (2010) designed and synthesized a series of structurally diverse heterocycle substituted phthalimide derivatives including furan, imidazo-[1,2-a]-pyridine, 1,3,4-thiadiazine, imidazo-[2,1-b][1,3,4]-thiadiazine, pyrazole, thiazole, thiazoline, etc by the reactions of $\alpha$-bromoketone intermediate with various nucleophiles containing oxygen, nitrogen and sulfur atom. Their cytotoxic activities were also evaluated against five human cancer cell lines in vitro and were found to be potent. The researchers concluded that a large number of structurally diverse phthalimide derivatives for drug development can be synthesized by this method.

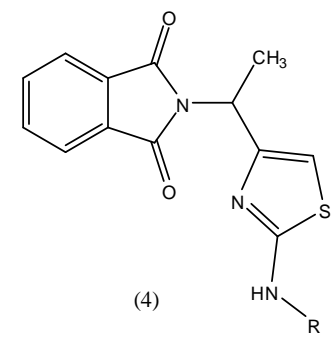

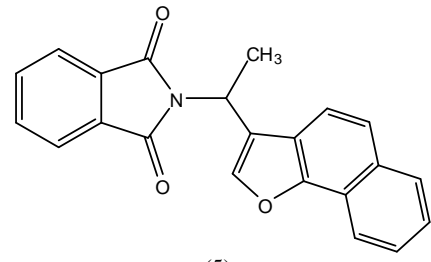

(5)

Selvum et al., (2013) reported some new N-substituted phthalimide derivatives (compound $\mathbf{6}$ and 7) been synthesized by condensation of phthalic anhydride and primary amines. Synthesized compounds were screened for antiviral activity against HIV-1 and -2 replication in MT-4 cells. Cytotoxicity was also investigated in uninfected MT-4 cells. All the synthesized compounds exhibited cytotoxicity in MT-4 cells $\left(\mathrm{CC}_{50}: 84-125 \mu \mathrm{g} /\right.$ $\mathrm{ml})$.

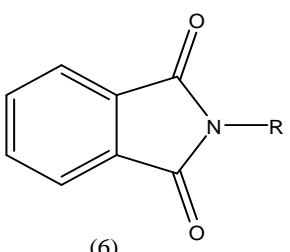

(6)

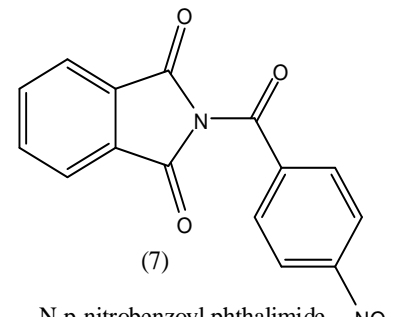

$\mathrm{N}$-substituted phthalimide derivatives<smiles>[R]Cc1cccc(-c2csc(C)n2)c1</smiles>

Chan et al., (2008) carried out 'one pot' condensation reaction for the synthesis and potent antiproliferative inhibition of a phthalimide based ketones. One of the molecule, 2-Phthalimide1-(4-fluoro-phenyl) ethanone, had the best growth inhibition on human MDAMB-231 breast carcinoma and SKHep-1 hepatoma cell lines. The bioactivity of the molecule was reported to be due to the presence of strong electronegative fluorine group at the para-position of the aryl ring (compound 8 ).<smiles>O=C([Al])[X]N1C(=O)c2ccccc2C1=O</smiles>

(8)
$\mathrm{X}=\mathrm{CH}_{2}, \mathrm{CH}\left(\mathrm{CH}_{3}\right)$ $\mathrm{Ar}=\mathrm{Ph}, 4-\mathrm{F}-\mathrm{Ph}$ 


\section{Antimicrobial activity}

Pawar et al., (2012) synthesized and investigated structural modifications of phthalimide to various $\mathrm{N}$-alkyl (compound 9) and $N$-alkyloxy derivatives (compound 10) have been reported to result in modification of biological activity. $\mathrm{N}$ alkyl and $\mathrm{N}$-alkyloxy produce potent fungicidal action due to which they are extensively used as pesticides, preservatives as well as pharmaceuticals.

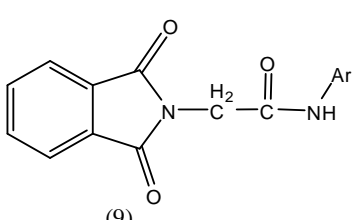

(9)

N-alkyl phthalimide

$\mathrm{Ar}=-\mathrm{C}_{6} \mathrm{H}_{5},-\mathrm{p}-\mathrm{CH}_{3}-\mathrm{C}_{6} \mathrm{H}_{4},-\mathrm{p}-\mathrm{OCH}_{3}-\mathrm{C}_{6} \mathrm{H}_{4}$, $-\mathrm{o}-\mathrm{OCH}_{3}-\mathrm{C}_{6} \mathrm{H}_{4},-\mathrm{p}-\mathrm{NO}_{2}-\mathrm{C}_{6} \mathrm{H}_{4},-\mathrm{C}_{10} \mathrm{H}_{7}$

Atukuri et al., (2011) demonstrated that 1, 2, 4triazolinone derivatives of phthalimide (compound $\mathbf{1 1} \mathbf{a}-\mathbf{j}$ ) possess antitubercular activity.

The anti-tubercular activity of the test compounds were evaluated against standard strain of Mycobacterium tuberculosis H37Rv (ATCC-27294) in BACTEC 12B medium using the microplate Alamar blue assay (MABA).29-30Antibiotic standard used was streptomycin at $6.5 \mu \mathrm{g} / \mathrm{mL}$ concentration. The compounds were tested at $5,10,15,20,25,30 \mu \mathrm{g} / \mathrm{mL}$ concentrations by serial dilution against the $\mathrm{M}$. tuberculosis H37Rv to determine minimum inhibition concentration (MIC) using MABA.

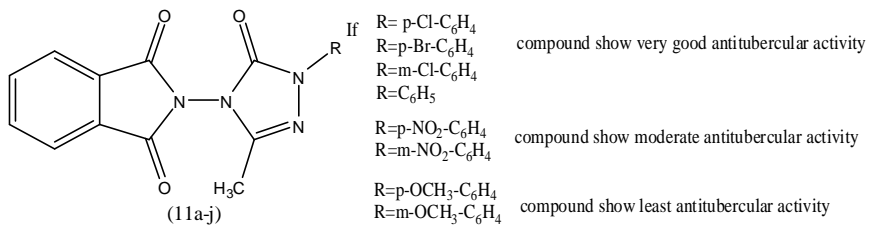

Table 2: Antitubercular activity of synthesized compounds (11a-j)

\begin{tabular}{cll}
\hline Compound & $\mathbf{R}$ & MIC $(\boldsymbol{\mu g} / \mathbf{m l})$ \\
\hline $11 \mathrm{a}$ & $\mathrm{C}_{6} \mathrm{H}_{5}$ & 06.6 \\
$11 \mathrm{~b}$ & $p-\mathrm{CH}_{3} \mathrm{C}_{6} \mathrm{H}_{4}$ & 07.3 \\
$11 \mathrm{c}$ & $p-\mathrm{ClC}_{6} \mathrm{H}_{5}$ & 05.7 \\
$11 \mathrm{~d}$ & $p-\mathrm{OCH}_{3} \mathrm{C}_{6} \mathrm{H}_{4}$ & 21.0 \\
$11 \mathrm{e}$ & $p-\mathrm{BrC}_{6} \mathrm{H}_{4}$ & 05.3 \\
$11 \mathrm{f}$ & $m-\mathrm{CH}_{3} \mathrm{C}_{6} \mathrm{H}_{4}$ & 07.2 \\
$11 \mathrm{~g}$ & $m-\mathrm{ClC}_{6} \mathrm{H}_{4}$ & 05.2 \\
$11 \mathrm{~h}$ & $m-\mathrm{OCH}_{3} \mathrm{C}_{6} \mathrm{H}_{4}$ & 23.0 \\
$11 \mathrm{i}$ & $p-\mathrm{NO}_{2} \mathrm{C}_{6} \mathrm{H}_{4}$ & 15.0 \\
$11 \mathrm{j}$ & $m-\mathrm{NO}_{2} \mathrm{C}_{6} \mathrm{H}_{4}$ & 18.0 \\
Standard & Streptomycin & 06.5
\end{tabular}

All compounds were tested at $5,10,15,20,25,30 \mu \mathrm{g} / \mathrm{mL}$ concentrations by serial dilution.

Bhambhi et al., (2009) reported that alkoxy derivative of phthalimide (compound 12 and 13) possess potent fungicidal, trypanocidal, they inhibit the growth of Plasmodium falciparum.
The synthesized compounds were tested for their biological activity against bacteria and fungi.
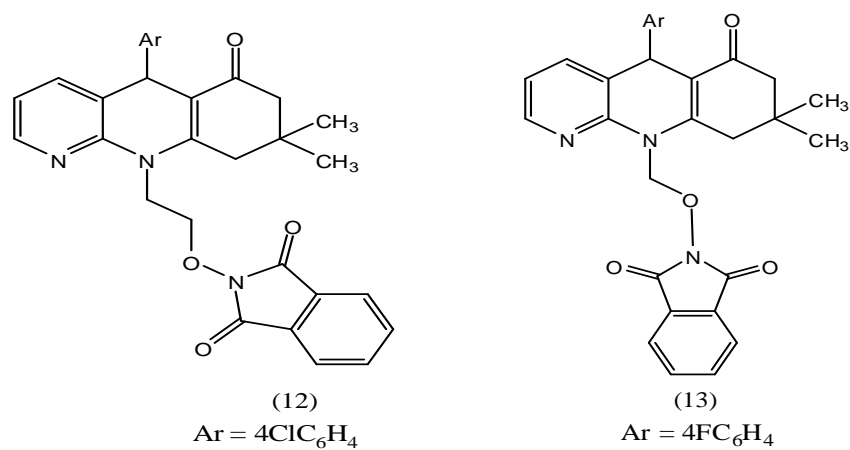

Santos et al., (2009) synthesized a series of phthalimide derivatives. All compounds were evaluated against Mycobacterium tuberculosis $\mathrm{H}_{37} \mathrm{Rv}$ using Alamar Blue susceptibility. They suggested that the lead compounds have the potency in the treatment of tuberculosis and multi-drug resistant tuberculosis.

It has been shown that hybridization of both phthalimide (Thalidomide) and sulfonamide (Dapsone) moiety leads to compounds with activity against $M$. leprae. In this sense, the design of new products such as anti-TB agents is interesting. SAR study of a series of derivatives (compound 14) showed that if the pyrimidine ring is substituted in any position or changed by an isosteric, this decreases activity on M. tuberculosis. Amino group substitutions by another phthalimide ring also lead to a decrease in anti-TB activity. Modifications in the pyridine ring decrease antiTB activity. Introduction of a phthalimide group by molecular hybridization did not produce compounds with an activity similar to INH.
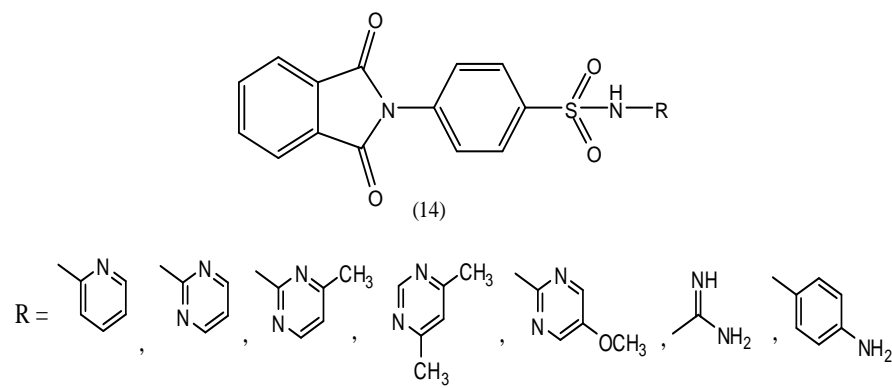

Anticonvulsant activity

Bhat et al., (2010) synthesized and demonstrated a series of novel 1,3,4-oxadiazole derivatives of phthalimide and evaluated their anticonvulsant and neurotoxicity studies. Compound having methoxy substitution at para position of the distal aryl ring emerged as most promising anticonvulsant agent with low neurotoxicity. The presence of methoxy group in ring B causes more lipophilic character of the molecule. Distal hydrophobic center alters the bioavailibility of compounds. It was established fact that there are at least four parameters for anticonvulsant drugs: lipophilic domain, distal aryl ring 
(hydrophobic centre) whose size effects pharmacokinetic properties, (-CONH) acts as hydrogen donor, an electron donor $(\mathrm{C}=\mathrm{N})$ system is also present.

Phthalimide derivatives of 1, 3, 4-oxadiazole (compound 15a-j) were screened for anticonvulsant activity. All the compounds were active in MES test, making them useful for broad spectrum of seizure type.

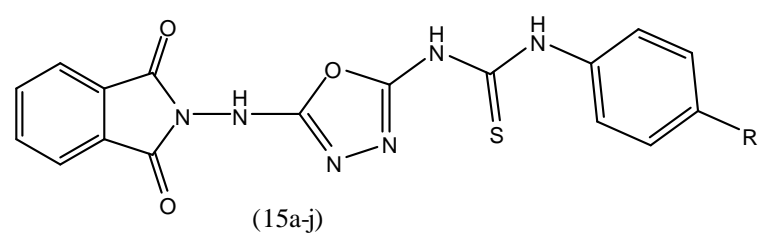

1,3,4-Oxadiazole derivatives of phthalimide.

15a: $\mathrm{R}=\mathrm{H} ; 15 \mathbf{b}: \mathrm{R}=2-\mathrm{Cl} ; \mathbf{1 5}$ c: $\mathrm{R}=3-\mathrm{Cl} ; \mathbf{1 5 d}: \mathrm{R}=4-\mathrm{Cl} ; 15$ e: $\mathrm{R}=2-\mathrm{CH} 3 ; 15$ f: $\mathrm{R}=3-\mathrm{CH} 3 ; \mathbf{1 5} \mathbf{g}$ : R=4-CH3; 15h:R=2-OCH3; 15i: R=3-OCH3;15j: R=4-OCH3.

Table 3: Anticonvulsant and neurotoxicity results of the titled compounds (15a-j).

\begin{tabular}{|c|c|c|c|c|}
\hline \multirow{3}{*}{ Compound } & \multicolumn{4}{|c|}{ Intrperitoneal injection in Mice ${ }^{\mathrm{a}}$} \\
\hline & \multicolumn{2}{|c|}{ MES Screening } & \multicolumn{2}{|c|}{ Toxicity Screening } \\
\hline & $0.5 \mathrm{~h}$ & $4 \mathrm{~h}$ & $0.5 \mathrm{~h}$ & $4 \mathrm{~h}$ \\
\hline $15 \mathbf{a}$ & 300 & 300 & 300 & 300 \\
\hline $15 \mathrm{~b}$ & 300 & 300 & 300 & 300 \\
\hline $15 \mathrm{c}$ & 300 & 300 & 300 & 100 \\
\hline $15 \mathrm{~d}$ & 300 & 300 & 300 & 300 \\
\hline $15 \mathrm{e}$ & 300 & 300 & 300 & 300 \\
\hline $15 \mathrm{f}$ & 300 & 300 & 300 & - \\
\hline $15 \mathrm{~g}$ & 100 & 300 & 100 & 300 \\
\hline $15 \mathrm{~h}$ & 100 & 300 & 300 & 300 \\
\hline $15 \mathrm{i}$ & 100 & 300 & 300 & - \\
\hline $15 \mathrm{j}$ & 30 & 300 & 300 & - \\
\hline Phenytoin $^{\mathrm{b}}$ & 30 & 30 & 100 & 100 \\
\hline Carbamazepine $^{\text {b }}$ & 30 & 100 & 100 & 300 \\
\hline Phynobarbital $^{\text {b }}$ & 100 & 30 & 100 & 300 \\
\hline
\end{tabular}

Bhat et al., (2011) synthesized and investigated Schiff bases (compound 16) with phthalimide pharmacophore and evaluated for anticonvulsant and neurotoxic properties. Anticonvulsant screening was performed using MES test. All the Schiff bases of phthalimides were active in the MES test indicative of their ability to prevent seizure spread. All the compounds were less neurotoxic than phenytoin. The evaluation of compounds indicated the importance of the size of the group at the carbimino carbon atom. Replacement of the hydrogen atom on the carbimino carbon atom by methyl group is leading to an increase in the size at this position of the molecule and has shown a change in activity. This modification may increase the anticonvulsant activity because of additional vander walls bonding or alternately steric impedance to alignment at the binding site causing lower activity or its loss. The attachment of distal aryl ring to the proximal aryl ring increases the vander Walls bonding at the binding site and increases potency. The distal aryl ring at carbimino terminal (benzylidene ring) is essential for the pharmacokinetic properties of compounds since the variation in the substitution at the distal

aryl ring was found to affect biological activity. During metabolism, the distal aryl ring is expected to be p-hydroxylated. Introduction of nitro substitution showed more protection at as compared to methyl, chloro and hydroxy substitution at distal aryl ring. Compound with nitro substitution at ortho-position of distal aryl ring have emerged as the most promising anticonvulsant agent with low neurotoxicity.

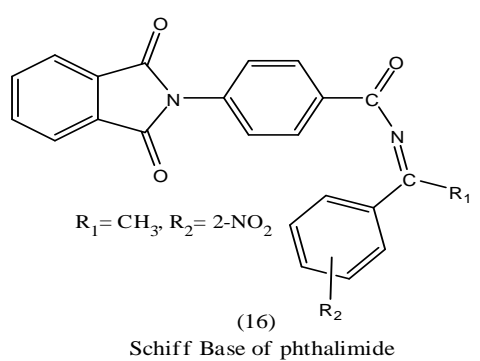

Arti et al., (2011) synthesized and reported that substituted 4-Pthalamido-N-Phenyl-benzene sulphonamide (compound 17a-e) derivatives possessed anticonvulsant activity which was evaluated by MES (maximal electric shock-induced seizure) method. In substituted phthalimido sulphonamide series aniline derivative showed least anti-convulsant activity (i.e., $\mathrm{R}=\mathrm{H}$ ), but 4-nitro derivatives $\left(\mathrm{R}=\mathrm{NO}_{2}\right)$ were found to be effective than chloro derivatives $(\mathrm{R}=\mathrm{Cl})$. Electron withdrawing nitro derivatives were found to be effective than electron donating aniline derivative which were found to be ineffective.

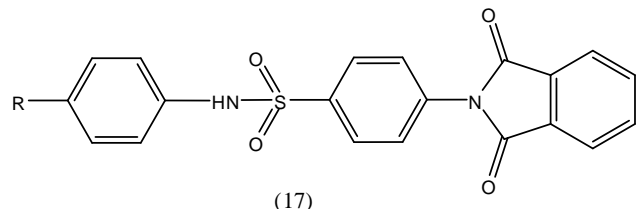

Substituted 4-Pthalamido-N-Phenylbenzenesulphonamide

17a: H 17b: 4-NO2 17c: 4-Br 17d: 4-Cl 17e: 2-Cl

Wiecek et al., (2009) synthesized two series of phthalimides one that possessed an $N$-phenoxyalkyl moiety sustituted at position 3 or 4 of the phenyl ring and a series of $\mathrm{N}$ alkenyl or alkinyl phthalimides (compound 18). They evaluated their anticonvulsant activity and estimated their lipophilicity in silico using computer programs. The anticonvulsant activity of phthalimides containing an unsaturated substituent at the phthalimide nitrogen was superior to that of the N-phenoxyalkyl phthalimides.

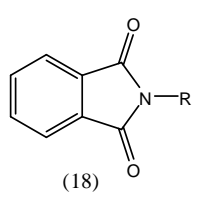

(18)

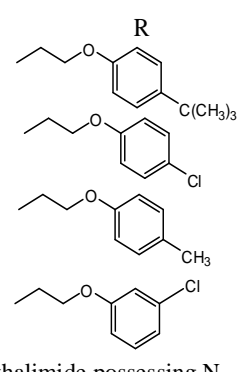

Phthalimide possessing Nphenoxyalkyl moiety substitute at position 3 or 4 of the phenyl ring
$\mathrm{R}$

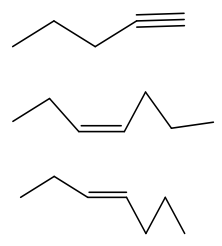

$\mathrm{N}$-alkenyl or alkinyl phthalimides 
Khan et al., (2009) synthesized and evaluated a series of 4-(5-bromo-1,3-dioxo -1,3-dihydro-2H-isoindol-2-yl)-butyryl $N$-(substituted phenyl) amides (compound 19) for their anticonvulsant activity in MES test according to the protocols of Antiepileptic Drug Development (ADD) programme of National Institutes of Health (NIH, Bethesda, USA). The studies revealed that the alkyl substitution at the aromatic ring was essential for activity being lipophilic in nature.

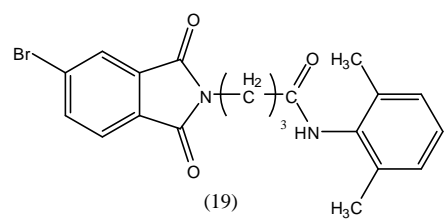

\section{Anxiolytic activity}

Hassanzadeh et al., (2007) synthesized and evaluated $N$ Benzoyl phthalimide and N-Benzylphthalimide for their anxiolytic activity and demonstrated that N-Benzoyl Phthalimide possesses excellent anxiolytic activity. N-Benzoyl-3-nitrophthalimide (compound 21) showed a lower activity compare to that of diazepam and $\mathrm{N}$-benzoylphthalimide (compound 20). An electron withdrawing group $\left(\mathrm{Cl}, \mathrm{NO}_{2}\right)$ on $\mathrm{C}_{7}$ of benzodiazepines is essential for sedative and anxiolytic activities of classic benzodiazepine agonists. Substitution of $\mathrm{Cl}$ or $\mathrm{NO}_{2}$ on other positions of the aromatic ring $(6,8$, and 9$)$ of benzodiazepines dramatically reduce activity. Reduction in activity of N-benzoyl 3-nitro-phthalimide might be due to the improper accommodation of electron withdrawing group $\left(\mathrm{NO}_{2}\right)$ in the benzodiazepine active site. Substitution of an electron donating group $\left(\mathrm{CH}_{3}\right)$ on the $\mathrm{C}$ ring of the parent compound in $\mathrm{N}$-(4'-methylbenzoyl)-phthalimide (compound 22) and N-(4'-methylbenzoyl)-3-nitro-phthalimide (compound 23) were also in favor for anxiolytic activity, this also has been seen in benzodiazepine series. Substitution at the 4'(para)-position of the phenyl ring of benzodiazepines is unfavorable for agonist activity; however, 2'-(ortho)-substituents are not detrimental to agonist activity.

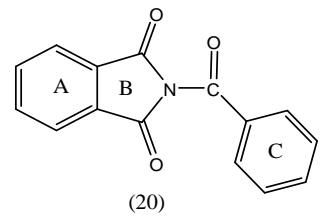

N-Benzoyl Phthalimide

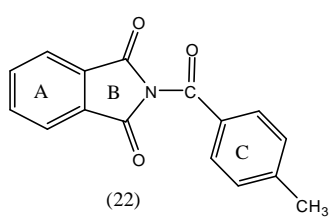

N-(4'-Methylbenzoyl)-phthalimide

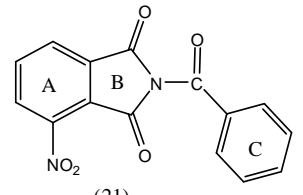

(21)

N-Benzoyl 3-Nitro-Phthalimide.

N-(4'-Methylbenzoyl)-3-Nitro-phthalimide

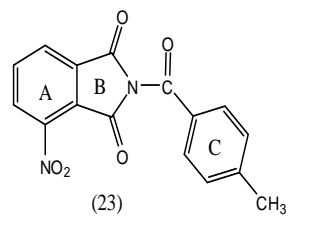

$\mathrm{N}$-Benzyl 3-nitro-phthalimide (compound 25) distorted from planarity due to the change of $\mathrm{C}=\mathrm{O}$ group of $\mathrm{N}$-benzoyl phthalimide to $\mathrm{CH}_{2}$ group. This distortion probably prevents the accommodation of the compound with its receptor and makes the compound ineffective as an anxiolytic agent. In benzodiazepines, the phenyl ring is attached directly to the ring B and its relationship to the ring a planarity may be important for agonist activity.

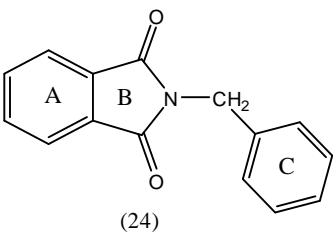

N-Benzyl Phthalimide

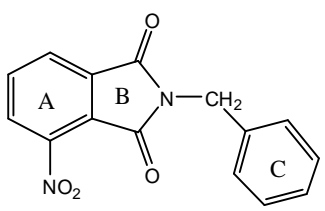

(25)
N-Benzyl 3-Nitro-Phthalimide

\section{$\alpha$-Glucosidase inhibitory activity}

Ibrahim Ali et al., (2009) demonstrated that $N$-Phenyl-3, 4, 5, 6-tetrachlorophthalimide and N-(4-phenylbutyl)-3, 4, 5, 6tetrachloro-phthalimide (compound 26) showed very potent $\alpha$ Glucosidase inhibitory activity. Potency of tricyclic phthalimide derivatives could be achieved by increasing the overall lipophilicity of the molecules and by incorporating halogen substituents in the benzylic aromatic ring attached to the phthalimido nitrogen atom.

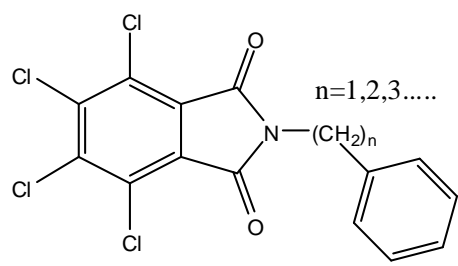

(26)

Pascale et al., (2010) synthesized and investigated alpha glucosidase inhibitors, bearing a phthalimide moiety connected to a variously substituted phenoxy ring by an alkyl chain that inhibited alpha glucosidase which is the key enzyme which catalyzes the final step in the digestive process of carbohydrates in mammalians. Hence, alpha glucosidase inhibitors can retard the liberation of D-glucose of oligosaccharides and disaccharides from dietary complex carbohydrates and delay glucose absorption, resulting in reduced postprandial plasma glucose levels and suppressed postprandial hyperglycaemia.

In particular, basing on pharmacological studies involving thalidomide, it was found that phenyl alkyl tetrachlorophthalimide derivatives exhibited potent $\alpha$-glucosidase inhibition. The structure activity relationship studies revealed the importance of the distance between the phthalimide ring and the phenyl moiety and the positive influence of electron withdrawing groups attached to the phthalimide moiety. Although tetrachlorophthalimide skeleton is a useful non-sugar type sugar mimic pharmacophore, the above mentioned compounds are characterized by high lipophilicity which could influence their pharmacokinetic properties and biological activity. A large series of phenoxyalkyl derivatives (compound 27), bearing a non- 
substituted phthalimide moiety, were prepared in order to investigate structure activity relationships and improve $\alpha$ Glucosidase inhibitory activity. In particular, the effects of substitutions at the aryloxy moiety and the length of the methylene spacer between the phthalimide group and the phenoxy moiety were investigated.

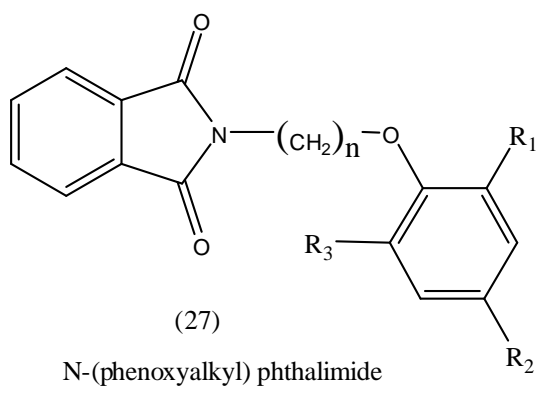

The length of the methylene spacer seems to be critical for enzyme inhibition. The potency of the $\alpha$-glucosidase inhibitory activity increased as the length of the methylene spacer increased to $\mathrm{n}=10$. Introduction of a chlorine atom at the para-position $\left(\mathrm{R}_{2}=\right.$ $\mathrm{Cl}$ ), caused the enhancement of the activity, which seemed to be further increased by the introduction of one or two additional methyl groups at the ortho-positions $\left(\mathrm{R}_{1}=\mathrm{R}_{2}=\mathrm{CH}_{3}\right)$.

In $N$-(phenoxydecyl) phthalimide derivatives (compound 28), presence of an electron withdrawing group $\left(\mathrm{NO}_{2}, \mathrm{CF}_{3}\right.$ etc.) at the 4-position $\left(\mathrm{R}_{3}\right)$ were more potent than the corresponding 4methyl derivative. Introduction of a nitro group at the ortho position $\left(\mathrm{R}_{1}\right)$ of markedly enhanced the activity giving the most potent compound. However presence of two strong electronwithdrawing groups at the phenoxy ring simultaneously did not increase the activity.

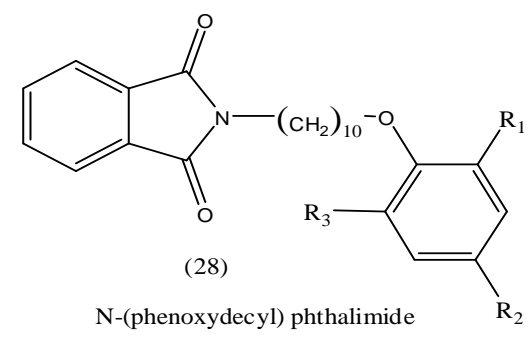

\section{Anti inflammatory activity}

Qaisi Jinan et al., (2011) evaluated amino acetylenic isoindoline derivative (compound 29a-d) for anti-inflammatory activity.

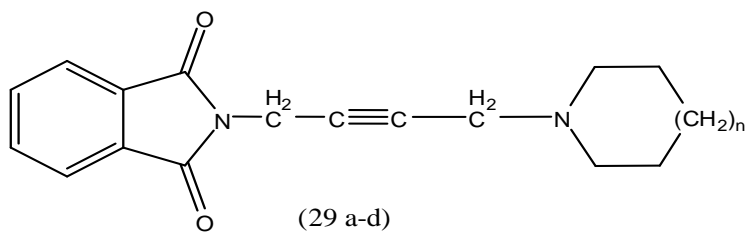

aminoacetylenic isoindoline derivatives
Table 4: Aminoacetylenic isoindoline derivatives.

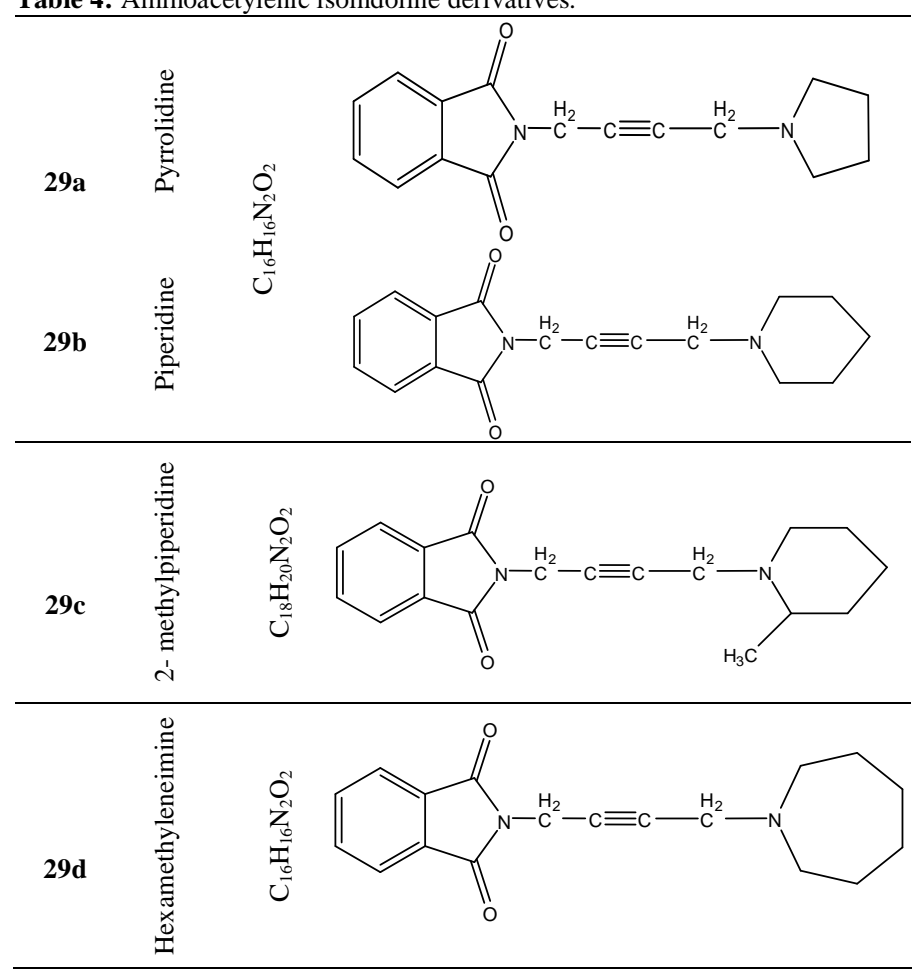

Table 5: The percent inhibition of COX-1 activity by different concentration of 29 (a-d) compounds using COX inhibition immunoassay (EIA) as compared with Diclofenac. Each value represents the mean \pm SD.

\begin{tabular}{cccc}
\hline \multirow{2}{*}{ Compound } & \multicolumn{3}{c}{ Concentration } \\
\cline { 2 - 4 } & $\mathbf{2 \mu \mathbf { M }}$ & $\mathbf{5 \mu} \mathbf{M}$ & $\mathbf{1 0} \boldsymbol{\mu} \mathbf{M}$ \\
\hline $\mathbf{2 9 a}$ & $12.5 \pm 7.5$ & $73.7 \pm 12.6$ & $25.5 \pm 3.5$ \\
$\mathbf{2 9 b}$ & $28.1 \pm 1.0$ & $72.5 \pm 20.5$ & $29.0 \pm 1.0$ \\
$\mathbf{2 9 c}$ & $30.5 \pm 1.0$ & $72.5 \pm 18.0$ & $8.0 \pm 2.0$ \\
$\mathbf{2 9 d}$ & $20.5 \pm 0.5$ & $74.5 \pm 14.3$ & $20.5 \pm 0.5$ \\
Diclofenac & $73.1 \pm 3.1$ & $99.44 \pm 0.2$ & $98.0 \pm 0.2$ \\
\hline
\end{tabular}

Stewart et al., (2010) demonstrated that thalidomide analogues (compound 30, 31) containing either a phenyl or alkyne using Sonogashira and Suzuki cross coupling reactions from their aryl halogenated precursors.

All the thalidomide analogues were evaluated for their ability to inhibit the expression of the proinflammatory cytokine Tumor Necrosis Factor (TNF). Orzeszko et al., (2010) Compounds containing an aryl-isobutyl or arylisopropoxy groups were reported to be several times more active than thalidomide in inhibiting TNF expression and apoptotic response.<smiles>O=C1CCC(N2C(=O)c3ccc(/C=C/CO)cc3C2=O)C(=O)N1</smiles>

Sharma et al., (2012) synthesized novel schiff bases of imide moiety (compound 32) which exhibited anti-inflammatory and analgesic activity. 


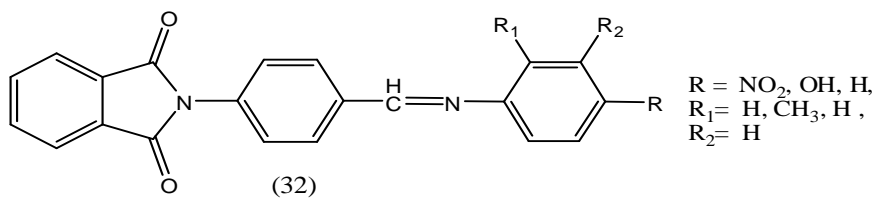

Shakir et al., (2007) synthesized aminoacetylenic isoindoline-1, 3-dione (compound 33) and showed their antiinflammatory activities by reducing carrageenan-induced rat paw edema and modulating proinflammatory and anti-inflammatory cytokines.

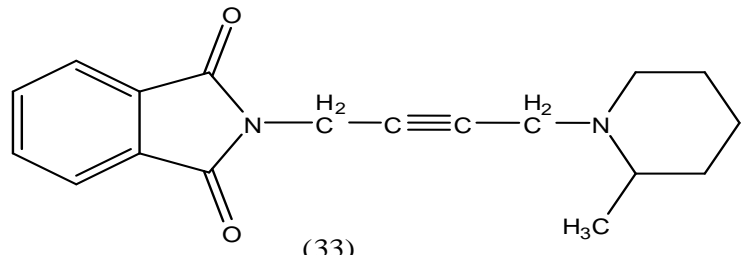

2-(4-(2-methylpiperidin-1-yl)but-2-ynyl)isoindoline-1,3-dione

Table 6: Rats Heamatologiacal parameters following a 10-days administration of compound 33.

\begin{tabular}{lllll}
\hline Parameter & Controle & & $\mathbf{3 3}$ & Compound \\
& & & $\mathbf{5 0 m g} / \mathbf{k g}$ & \\
\cline { 2 - 5 } & Males & Females & Males & Females \\
\hline RBC $\left(\mathrm{x} 10^{6} / \mu \mathrm{L}\right)$ & $5.5 \pm 0.2$ & $5.4 \pm 0.3$ & $6.2 \pm 0.1^{*}$ & $8.4 \pm 0.8^{*}$ \\
$\mathrm{HB}(\mathrm{g} / \mathrm{dL})$ & $14.3 \pm 0.4$ & $14.2 \pm 0.6$ & $15.2 \pm 0.3$ & $21.2 \pm 1.6^{* *}$ \\
$\mathrm{PCV}(\%)$ & $29.6 \pm 0.2$ & $29.4 \pm 1.0$ & $31.0 \pm 0.6$ & $42.9 \pm 3.3^{*}$ \\
$\mathrm{WBC}\left(\mathrm{x} 10^{3} / \mu \mathrm{L}\right)$ & $10.5 \pm 1.3$ & $6.3 \pm 0.2$ & $9.2 \pm 1.0$ & $7.9 \pm 1.2$ \\
Neutrophil $(\%)$ & $9.8 \pm 1.9$ & $11.7 \pm 1.2$ & $12.9 \pm 1.3$ & $15.1 \pm 1.7$ \\
Lymphocytes $(\%)$ & $78.0 \pm 3.2$ & $74.2 \pm 1.8$ & $72.3 \pm 2.7$ & $70.1 \pm 3.2$ \\
Monocytes $(\%)$ & $12.2 \pm 1.9$ & $14.1 \pm 1.2$ & $14.8 \pm 1.5$ & $14.9 \pm 1.6$ \\
Platelets $\left(\mathrm{x} 10^{3} / \mu \mathrm{L}\right)$ & $663 \pm 138$ & $780 \pm 96$ & $904 \pm 182$ & $679 \pm 105$ \\
\hline
\end{tabular}

\section{Anti viral activity}

Anti HIV activity

Bansal et al., (2007) demonstrated that increased HIV-1 inhibitory potency of tricyclic phthalimide derivatives could be achieved by increasing the overall lipophilicity of the molecules and by incorporating halogen substituents in the benzylic aromatic ring attached to the phthalimido nitrogen atom. Molecular flexibility and hydrophobicity predominantly govern the integrase inhibitory activity of phthalimides. Molecular flexibility increases with the number of flexible bonds in the molecule and the importance associated with flexible bond might be owing to the fact that they play an important role in the orientation of pharmacophoric groups in the active site of the enzyme. Hydrophobic substituents in the molecule might influence enzyme-drug affinity through non-specific interactions with hydrophobic region in the active site of the enzyme. Furthermore, it appears that the halogen substitution in the phenyl ring plays a significant role molecule enzyme affinity, a fact reflected in increased integrase inhibitory potency exhibited by molecules with halogen substituents (compound 34 a-z). Presence of bulky groups and electronegative atoms in the molecule disfavors the HIV-1 integrase inhibitory affinity of the title compounds.

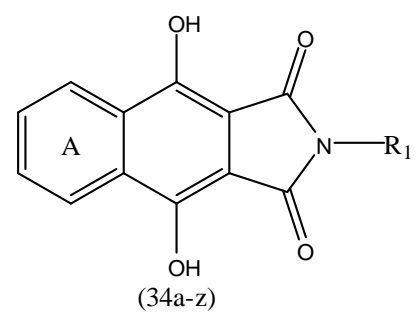

Table 7: Sructural modification and HIV-1 integrase inhibition data of trycyclic pthalamide analogues $34 \mathrm{a}-\mathrm{Z}$.

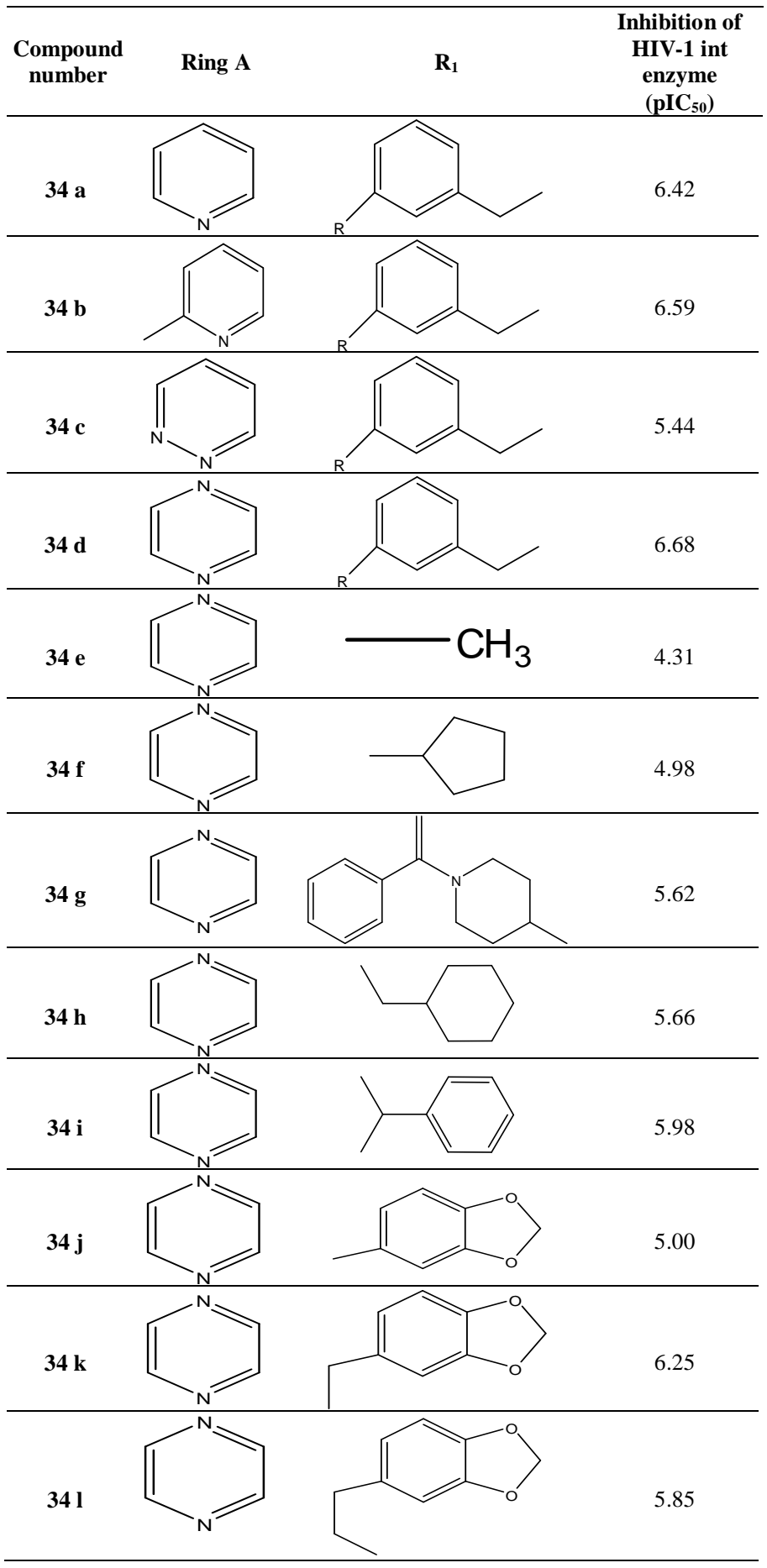




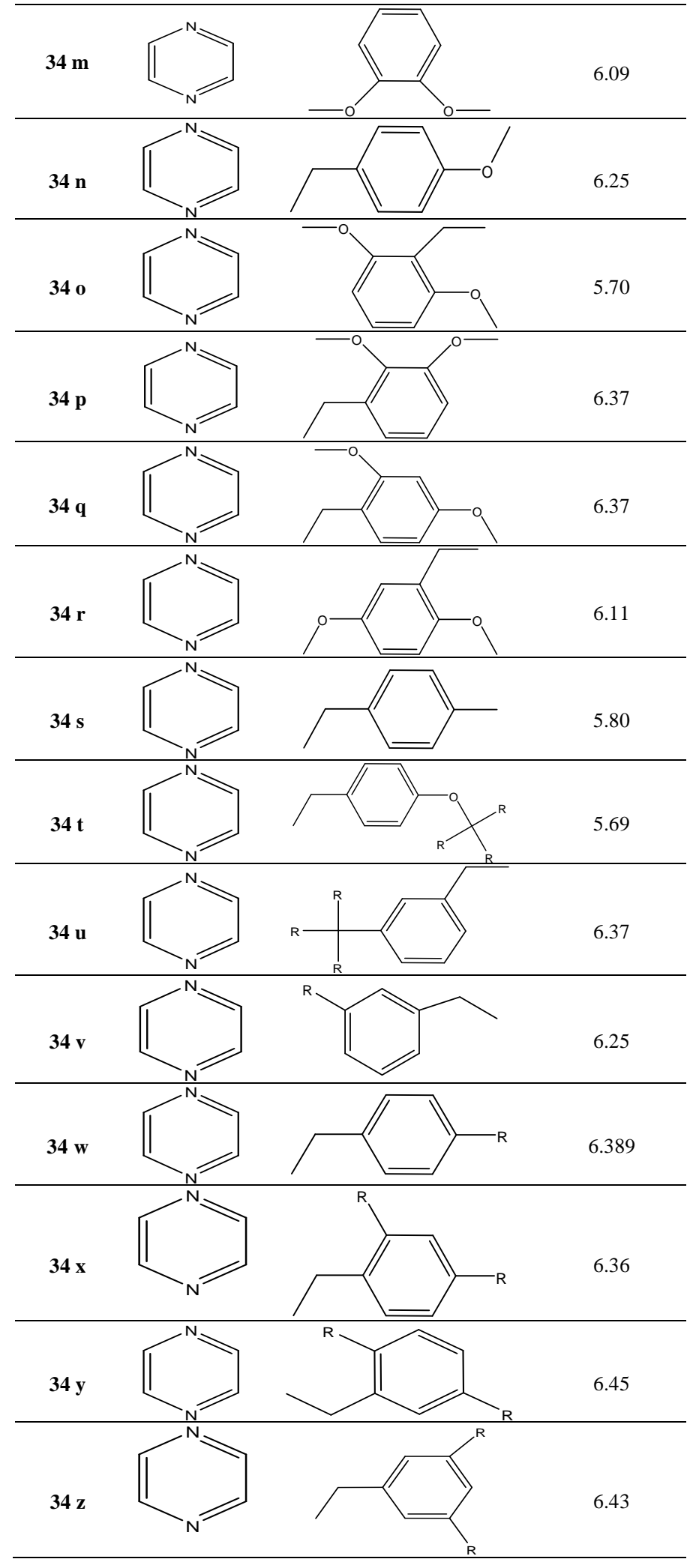

Yang et al., (2010) investigated series of phthiobutazone analogues, prepared from potassium phthalimide or phthalandione, have been evaluated for their antiviral activities. Among the candidates, compounds which contain the substituted 4- halogenated phenyl ring (compound 35 a-o), show more potent antiviral activity against herpes simplex virus.

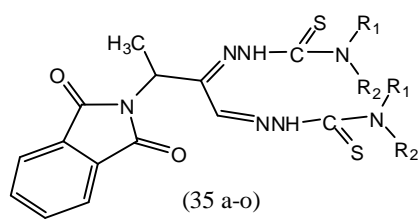

Table 8: Anti-HSV Activity $(\mu / \mathrm{ml})$ and Selectivity Index of Compounds 35 a-o in-vitro

\begin{tabular}{|c|c|c|c|c|c|c|c|}
\hline \multirow{2}{*}{$\begin{array}{l}\text { Comp } \\
\text { ound }\end{array}$} & \multirow{2}{*}{$\mathbf{R}_{1}$} & \multirow{2}{*}{$\mathbf{R}_{2}$} & \multirow{2}{*}{$\mathrm{CC}_{50}{ }^{\mathrm{a})}$} & \multicolumn{2}{|c|}{ HSV-1 } & \multicolumn{2}{|c|}{ HSV-2 } \\
\hline & & & & $I^{(b 0)}$ & $\mathrm{SI}^{\mathrm{c})}$ & $\mathrm{IC}_{50}$ & SI \\
\hline 35 a & $\mathrm{Me}$ & $\mathrm{Me}$ & 21.37 & $>4.11$ & - & $\mathrm{NT}^{\mathrm{d})}$ & - \\
\hline $35 \mathrm{~b}$ & $\mathrm{H}$ & i-Pr & 74.07 & $>24.69$ & - & NT & - \\
\hline $35 \mathrm{c}$ & $\mathrm{H}$ & Cyclohexyl & 53.14 & $>12.34$ & - & NT & - \\
\hline $35 \mathrm{~d}$ & $\mathrm{H}$ & Allyl & 77.04 & $>111.11$ & - & NT & - \\
\hline $35 \mathrm{e}$ & $\mathrm{H}$ & $\mathrm{Bn}$ & 21.38 & $>12.34$ & - & NT & - \\
\hline $35 f$ & $\mathrm{H}$ & 4-Cl-Bn & 21.38 & 12.34 & _- & NT & - \\
\hline $35 \mathrm{~g}$ & $\mathrm{H}$ & $\mathrm{Ph}$ & 21.38 & 4.11 & 5.20 & NT & - \\
\hline $35 \mathrm{~h}$ & $\mathrm{H}$ & 2-F-Ph & 37.03 & 5.30 & 6.90 & NT & - \\
\hline $35 \mathrm{i}$ & $\mathrm{H}$ & 4-Br-Ph & 111.11 & 21.37 & 5.20 & 2.85 & 7.50 \\
\hline $35 \mathbf{j}$ & $\mathrm{H}$ & $4-\mathrm{F}-\mathrm{Ph}$ & 64.15 & 8.56 & 7.49 & 1.75 & 36.80 \\
\hline $35 \mathrm{k}$ & $\mathrm{H}$ & 4-Cl-Ph & 77.04 & 2.85 & 27.03 & 4.11 & 18.70 \\
\hline 351 & $\mathrm{H}$ & $3,4-\mathrm{Cl}, \mathrm{Cl}-\mathrm{Ph}$ & 333.33 & 25.68 & 13.00 & $>111.11$ & - \\
\hline $35 \mathrm{~m}$ & $\mathrm{H}$ & 3,5-CF3,F3-Ph & 53.41 & 12.34 & - & NT & \\
\hline $35 \mathrm{n}$ & $\mathrm{H}$ & 4-Me-Ph & 21.38 & $>12.34$ & - & NT & \\
\hline 35 o & $\mathrm{H}$ & 4-MeO-Ph & 21.38 & 12.34 & 1.73 & NT & \\
\hline TDA & $\mathrm{H}$ & $\mathrm{H}$ & 384.90 & 95.44 & 4.03 & 74.07 & 5.19 \\
\hline $\mathrm{ACV}$ & & & & 1.00 & & 8.98 & \\
\hline
\end{tabular}

a) CC50: 50\% cytotoxic concentration; b) IC: $50 \%$ Effective Concentration; c) SI $($ Selective Index $\left.)=\mathrm{CC}_{50} / \mathrm{IC}_{50} ; \mathrm{d}\right) \mathrm{NT}$ : Not tested

\section{Anti- influenza activity}

Yuma et al., (2010) identified potential and novel antiinfluenza agents by screening the synthesized phenethyl phenylphthalimide analogues (compound 36) on PA endonuclease inhibition assay and anti-influenza A virus assay. The four analogs were found to inhibit PA endonuclease and retard the growth of influenza A. The results also indicated that PA endonuclease assay may also be utilised in the screening of anti-influenza drugs and is useful for future strategies to develop novel anti-influenza A drugs and for mapping the function of the influenza A RNA polymerase subunits.

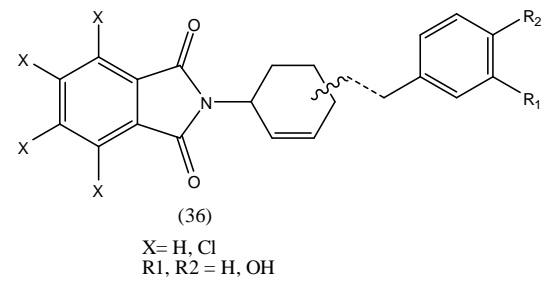

\section{Anti-Angiogenesis Activity}

Noguchi et al., (2005) revealed that 5-Hydroxy-2-(2, 6diisopropylphenyl)-1H-isoindole-1, 3-dione (compound 37), obtained from structural development studies on thalidomide, was found to possess potent anti-angiogenic activity in a human umbilical vein endothelial cell (HUVEC) assay. Thalidomide and its metabolite, 5-hydroxythalidomide (compound 38) showed weak or moderate activity in the same assay. 


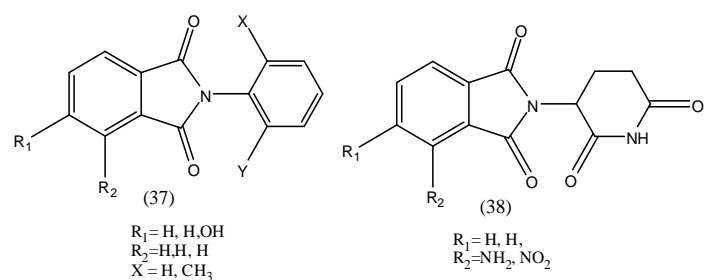

Nagarajan et al., (2013) synthesized benzothiazole and benzimidazole containing phthalimide derivatives $(39,40,41$ \& 42) and their anti-angiogenic activity was evaluated using ex vivo egg yolk angiogenesis model.

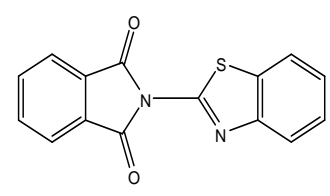

(39)
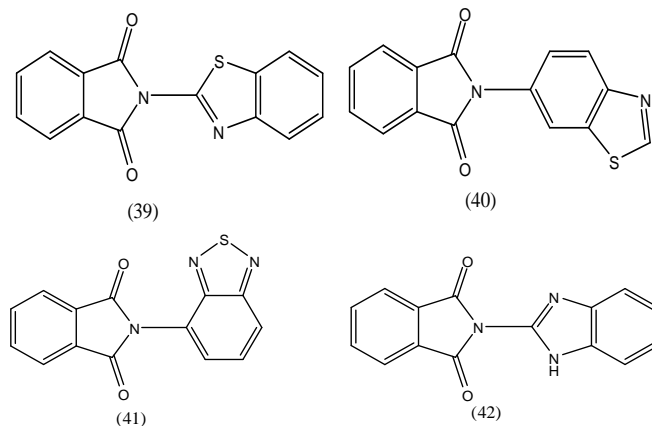

$(40)$

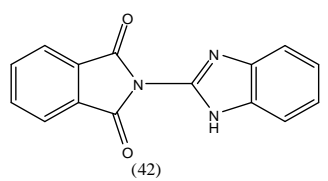

Histone deacetylase (HDAC) inhibitors

Chihiro et al., (2007) designed and synthesized several hydroxamic acid derivatives with a substituted phthalimide group (compound 43) as histone deacetylase (HDAC) inhibitors. Further, with SAR studies they concluded that the distance between the $\mathrm{N}$ hydroxyl group and the cap structure are important for HDACinhibitory activity.

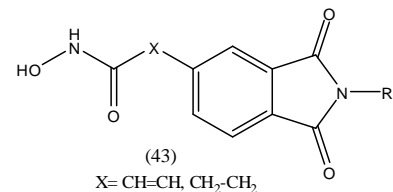

\section{Thromboxane inhibitory activity}

Yoshiaki et al., (1999) synthesized a series of novel 1isoindolinone derivatives, which inhibited the contraction of pig coronary artery induced by U-46619, a thromboxane A2 analogue. The activities of p-hydroxybenzyl type and p-hydroxyphenyl-ethyl type compounds 44,45 and 46 were inhibitory activity.
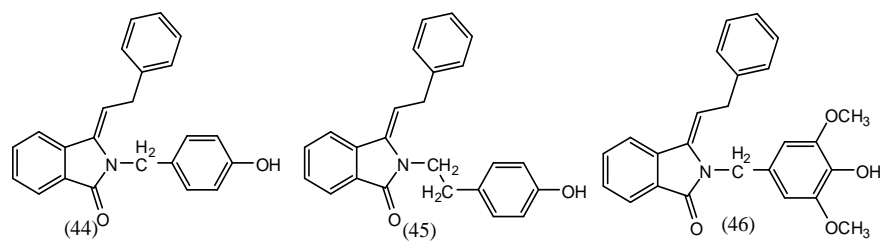

\section{CONCLUSION}

Among the bicyclic non aromatic nitrogen Heterocycles phalimide are an interesting class of compounds with a large range of applications. Phthalimides have served as starting materials and intermediates for the synthesis of many types of alkaloids and pharmacophores. Recently, phthalimide and some of its derivatives have proved to have important biological effects similar or even higher than known pharmacological molecules and so their biological activity is being a subject of biomedical research. Phthalimides have received attention due to their antibacterial, antifungal, analgesic, antitumour, anxiolytic and anti HIV-1 activities. The present review highlighted exclusively an important class of heterocyclic phthalimide derivatives that can be used as promising and effective drugs for the treatment of different diseases such as AIDS, tumor, diabetes, multiple myeloma, convulsion, inflammation, pain, bacterial infection among others. Thus phthalimide framework plays an immense role in biologically active compounds and therefore represents an interesting template for medicinal chemistry. This paper further shed light on the SAR of the synthesized compounds. Taken together, the examples presented in this paper showed an impressive impact of structural variations and the SAR analysis revealed that the activity profile of these scaffolds relies upon the position and nature of substituents on the parent skeleton, rendering numerous compounds more active as compared to standard drugs. The established track record of significant efforts toward phthalimide scaffolds with impressive therapeutic profile would be the important step to a possible drug development for treatment of many diseases and these comprehensive endeavors will open up new opportunities for researchers to design invaluable therapeutic agents phthalimide scaffold.

\section{REFERENCES}

Al-Qaisi JA, Alhussainy TM, Qinna NA, Matalka KZ, AlKaissi EN, Muhi-Eldeen ZA. Synthesis and pharmacological evaluation of aminoacetylenic isoindoline-1,3-dione derivatives as anti-inflammatory agents. Arabian J. Chemistry, 2011,4,1-7.

Arti Kumar S, Pathak D. Synthesis and Anticonvulsant screening of 4-Phthalim-ido - N-(4'- substitutesd Phenyl benzene sulphonamide, 4-Succnimido-N-(4'-substituted Ph-enyl) benzenesulphonamide. Int. J. of PharmTech Res., 2011, 3, 2104-2110.

Atukuri D, Kattimani P, Kamble R. Mg $\left(\mathrm{ClO}_{4}\right)_{2}$ catalyzed ecobenign synthesis of 1, 2, 4-triazolinone derivatives as anti-tubercular agents. Organic communications, 4, 94-104, (2011).

Azzawi AMA and Razzak MSA. Synthesis, Characterization and antibacterial activity of Several New Schiff Bases Linked to Phthalimide Moiety. Kar. J. Pharma. Sci., 2, 2011, 124-133.

Bansal R, Karthikeyan C, Moorthy NSHN, Trivedi P. QSAR analysis of some phthalimide analogues based inhibitors of HIV-1 integrase. ARKIVOC, 2007, 15, 66-81.

Barbosa MLC, Ramos TJF, de Arantes ACS, Martins MA, Silva PMR, Barreiro EJ, Lima LM. Synthesis and Pharmacological Evaluation of Novel Phenyl Sulfonamide Derivatives Designed as Modulators of Pulmonary Inflammatory Response. Molecules, 2012; 17(12):14651-72.

Bhambhi D, Salvi VK, Bapna A, Pemawat G. Talesara GL. Synthesis and antimicrobial of evaluation of some alkoxyphthalimide derivatives of Naphthyridine, Indian Journal of Chemistry, 2009, 48B, 697-704.

Bhat AM, Omar Al AM, Siddiqui N. Synthesis, anti-convulsant and neurotoxicity of some novel 1, 3, 4-oxadiazole derivatives of phthalimide, Der Pharma Chemica, 2010, 2, 1-10.

Bhat MA, Al-Omar MA. Synthesis, Characterization and In vivo Anticonvulsant and Neurotoxicity Screening of Schiff bases of 
Phthalimide, Acta Poloniae Pharmaceutica - Drug Research, 2011, 68, 375-380.

Chan SH, Lam KH, Chui CH, Gambari R, Yuen MC, Wong RS, Cheng GY, Lau FY, Au YK, Cheng CH, Lai PB, Kan CW, Kok SH, Tang JC, Chan AS. The preparation and in vitro antiproliferative activity of phthalimide based ketones on MDAMB-231 and SKHep-1 human carcinoma cell lines, Eur. J. Med. Chem., 2008, 44, 2736-2740.

Chiriac CI, Nechifor $\mathrm{M}$ and Tanasa F, Marioara $\mathrm{N}$ et al., Formamide, a novel challenging reagent for the direct synthesis of non-Nsubstituted cyclic imides, Rev. Roum. Chim., 2007, 52, 883-886.

EFSA (European Food Safety Authority), 2013, EFSA Journal, 2013, 11(12):3510, 1-33.

EFSA (European Food Safety Authority), 2014, EFSA Journal, 2014, 12(5):3700, 1-55

EFSA (European Food Safety Authority), 2014, EFSA Journal, 2014, 12(4):3663, 1-55

Hassanzadeh F, Rabbani M, Khodarahmi G A et al. Synthesis and Evaluation of the Anxiolytic Activity of Some Phthalimide Derivatives in Mice Model of Anxiety. Ira. J.Pharma.Sci.,2011,11,109115 .

Hassanzadeh F, Rabbani M, khodarahmi GA et al., Synthesis of phthalimide derivatives and evaluation of their anxiolytic activity. Res. in Pharma. Sci., 2007, 2, 35-41.

Ibrahim A A I, Fathalla W. Synthesis of N-substituted-3,4,5,6 tetra chloro- phthalimide using trichloroacetimidate $\mathrm{C}-\mathrm{C}$ bond formation method. ARKIVOC, 2009, 8, 193-199.

Jindal D P, Singh B, Coumar M S. Synthesis of 4-(benzamide)and 4-(phthalimide)-substituted phenoxy propanolamines and their $\beta 1$-, $\beta 2$-adrenergic receptor binding studies, Indian J. Chemistry, 2005, 44B, 1441-1445.

Kathuria V, Pathak D P, Synthesis and anticonvulsant activity of some N-substitutedphthalimide analogues, The Pharma Innovation, 2012, 1, 55-59.

Khan SA, Siddiqui N, Kamal M, Alam O, Jawaid $T$. Anticonvulsant and Neurotoxicity Evaluation of New Bromophthalimidobutyryl amide derivatives, Acta Poloniae Pharmaceutica, 2009, 66, 65-68.

Khidre R E, Abu-Hashem A A, El-Shazly M. Synthesis and anti-microbial activity of some 1- substituted amino-4,6-dimethyl-2-oxopyridine-3-carbonitrile derivatives. Eur. J. Med. Chem., 2011, 46, 50575064.

Sukhbir L. Khokra, Kanika Arora, Heena Mehta, Ajay Aggarwal and Manish Yadav. Common Methods to Synthesize Benzothiazole derivatives and their Medicinal Significance: A Review, Int. J. Pharm. Sci. Res., 2011, 2, 1356-1377.

Lima LM, Castro P, Machado AL, Fraga CA, Lugnier C, de Moraes VL, Barreiro EJ. Synthesis and anti-inflammatory activity of phthalimide derivatives designed as new thalidomide analogues. Bioorg. Med. Chem., 10, 2002, 3067-3073.

Mbarki S, Elhallaoui M. 3D-QSAR for $\alpha$-Glucosidase inhibitory activity of $\mathrm{N}$-(phenoxyalkyl) phthalimide derivatives. IJRRAS, 2012; 11, 395-401.

Nagarajan S, Majumder S, Sharma U, Rajendran S, Kumar N, Chatterjee S, Singh B. Synthesis and anti-angiogenic activity of benzothiazole, benzimidazole containing phthalimide derivatives, Bioorg. Med. Chem. Lett., 2013, 23, 287-290.

Noguchi T, Fujimoto H, Sano H, Miyajima A, Miyachi H, Hashimoto Y. Angiogenesis inhibitors derived from thalidomide, Bioorg. Med. Chem. Lett., 2005, 15, 5509-5513.

Noguchi T, Miyachi H, Katayama R, Naito M, Hashimoto Y. Cell differentiation inducers derived from thalidomide. Bioorg. Med. Chem. Lett., 2005, 15, 3212-3215.

Okunrobo LO, Usifoh CO, Scriba GKE. Synthesis and Pharmacological Evaluation of 2-hydroxy methyl benzamides as Antiinflammatory and Analgesic agents. Acta Poloniae Pharmaceutica, 2006, $63,25-31$.

Orzeszko A, Lasek W, Switaj T, Stoksik M, Kamińska B. Tumor necrosis factor-alpha production-regulating activity of phthalimide derivatives in genetically modified murine melanoma cells B78H1, Farmaco., 2003, 58, 371-376.

Pascale R, Carocci A, Catalano A, Lentini G, Spagnoletta A, Cavalluzzi MM, De Santis F, De Palma A, Scalera V, Franchini C. New $\mathrm{N}$-(phenoxydecyl)phthalimide deriva-atives displaying potent inhibition activity towards a-glucosidase. Bioorg. Med. Chem., 2010, 18, 5903-5914.

Pawar NS, Patil JU, Suryawanshi KC Chaudhary SR, Patil PB. An improved microwave irradiation met-hod for synthesis of some new $\mathrm{N}$ alkyl and N-alkyloxy phthalimides. Der Pharma Chemica, 2012, 4,15-22.

Raghad Shakir, Zuhair A. Muhi-eldeen, Khalid Z. Matalka, and Nidal A. Qinna. Analgesic and Toxicity Studies of Aminoacetylenic Isoindoline-1,3-dione Derivatives. ISRN Pharmacology, 2012, Article ID 657472,8 pages.

Ramesh M, Sabastiyan A. Synthesis, Characterization and Antimicrobial Studies on a New Mannich Base N(Morpholinomethyl)phthalimide and its Zinc(II), Cadmium(II) and Mercury(II) Complexes. Der Chemica Sinica, 2012, 3(5): 1297-1304.

Santos JL, Yamasaki PR, Chin CM, Takashi CH, Pavan FR, Leite CQ. Synthesis and in vitro anti Mycobacterium tuberculosis activity of a series of phthalimide derivatives, Bioorg. Med. Chem., 2009, 17, 3795-3799.

Schett G, Sloan V S, and Schafer P. Apremilast: a novel PDE4 inhibitor in the treatment of autoimmune and inflammatory diseases. Therapeutic advances in musculoskeletal disease, 2010, 2(5), 271-278.

Selvam P, Pannecouque C, De Clercq E. Synthesis, Anti HIV activity and Cytotoxicity of $\mathrm{N}$-Substituted Phthalimide derivatives. Int. J. of Pharmacy and Anal. Res., 2013, 2, 12-14.

Sharma S, Jain A D K, Aggarwal A et al. A Review: Synthesis and Biological Activity of Imides. The Global Journal of Pharmaceutical Research, 2012, 1(3), 411-421.

Sharma U, Kumar P, Kumar N, Singh B. Recent Advances in the Chemistry of Phthalimide Analogues and their Therapeutic Potential, Mini Rev. in Med. Chem., 2010, 10, 678-704.

Shinji C, Nakamura T, Maeda S, Yoshida M, Hashimoto Y, Miyachi H. Design and synthesis of phthalimide type histone deacetylase inhibitors. Bioorg.Med. Chem. Lett., 2005, 15, 4427-4431.

Jagadish Singh, Tanushree Singha, Arup Naskar, Mrityunjoy Kundu, Ranjit Kumar Harwansh, Arijit Mondal, Tirtha Ghosh and TK Maity. Synthesis and Anti-Proliferative Activity of Some isoindoline-1, 3 dione derivatives against Ehrlich's Ascites Carcinoma Bearing Mice Model. Pharmacologyonline, 2011; 2, 976-987.

Srinivasan R, Kumar KR, Kumar PP. Synthesis and Antimicrobial Activity of some new $\alpha \mathrm{N}$-phthilimido amino acids analogues. Int. J. ChemTech Res., 2010, 2, 895-898.

Kok SH, Gambari R, Chui CH, Yuen MC, Lin E, Wong RS, Lau FY, Cheng GY, Lam WS, Chan SH, Lam KH, Cheng CH, Lai PB, Yu MW, Cheung F, Tang JC, Chan AS. Synthesis and anticancer activity of benzothiazole containing phthalimide on human carcinoma cell lines, Bioorg. Med. Chem., 2008, 16, 3626-3631.

Stewart SG, Braun CJ, Ng SL, Polomska ME, Karimi M, Abraham LJ. New thalidomide analogues derived through Sonogashira or Suzuki reactions and their TNF expression inhibition profiles, Bioorg. Med. Chem., 2010, 18, 650-662.

Wiecek M and Kononowicz KK. Synthesis and Anticonvulsant Evaluation of some N-substituted phthalimides, Acta Poloniae Pharmaceutica, 2009, 66, 249-257.

Wu JJ, Huang DB, Pang KR, Hsu S, Tyring SK. Thalidomide: dermatological indications, mechanisms of action and side-effects, British Journal of Dermatology, 2005, 153, 254-273.

Yang Y, Zhao JH, Pan XD, Zhang PC. Synthesis and Antiviral Activity of Phthiobutazone Analogues. Chem. Pharm. Bull., 2010, 58 , 208-211.

Yang Ya-Jun, Ya N Yang, Jiang JS, Feng ZM, Liu HY, Pan $\mathrm{XD}$, Zhang PC. Synthesis and cytotoxic activity of heterocycle substituted phthalimide derivatives. Chinese Chemical Letters, 2010, 21, 902-904.

Yoshiaki Kato K, Takemoto M, Achiwa K, Synthesis and Inhibitory Activity of 1-Isoindolinone Derivatives Possessing Inhibitory Activity against Thromboxane A2 Analog (U-46619)-Induced 
Vasoconstriction, Chem. Pharm. Bull., 1999, 47, 529-535.

Yosuva S M, Sabastiyan A. Synthesis, characterization and antimicrobial activity of 2-(dimethylaminomethyl) isoindoline-1, 3-dione and its cobalt (II) and nickel (II) complexes, Int. J. of ChemTech Res., 2012, 4 (2), 805-815.

Iwai Y, Takahashi H, Hatakeyama D, Motoshima K, Ishikawa M, Sugita K, Hashimoto Y, Harada Y, Itamura S, Odagiri T, Tashiro M, Sei Y, Yamaguchi K, Kuzuhara T. Anti-influenza activity of phenethylphenyl-phthalimide analogs derived from thalidomide, Bioorg. Med. Chem., 2010, 18, 5379-5390.

How to cite this article:

Kushwaha N, Kaushik D. Recent Advances and Future Prospects of Phthalimide Derivatives. J App Pharm Sci, 2016; 6 (03): 159-171. 